\title{
MATERIAIS COMPÓSITOS À BASE DE GESSO E ISOPOR PARA CONSTRUÇÃO DE CASAS POPULARES
}

\begin{abstract}
M. C. MACEDO', L.G.M. SOUZA², I. R.B. GOMES', L.C. MEDEIROS ${ }^{2}$
${ }^{1}$ Instituto Federal do Rio Grande do Norte- Campus Santa Cruz

${ }^{2}$ Laboratório de Máquinas hidráulicas e Energia Solar- Universidade federal do Rio grande do Norte Miguel.cabral@ifrn.edu.br; Ivertonufrn@yahoo.com.br; Iguilherme@dem.ufrn.br; Coutinhoufrn@yahoo.com.br
\end{abstract} \\ Artigo submetido em setembro/2011 e aceito em dezembro/2011
}

\section{RESUMO}

A utilização de novas tecnologias com o uso materiais alternativos, que são ecologicamente corretos, é uma inovação para indústria da construção civil não só pelas suas excelentes propriedades, mas também pelo barateamento na construção. Esse artigo visa expor um novo tipo de material compósito para construção de casas populares de baixo custo, à base de isopor (poliestireno) e gesso, que possui composições (1.5:1),
$(1: 1),(1: 1,5)$ gesso com isopor, a fim de substituir os tijolos tradicionais de cerâmicos convencionalmente utilizados. Dados relativos aos ensaios de condutividade térmica e de compressão foram realizados. Foi demonstrado que o custo de fabricação desses tijolos alternativos é inferior ao do tijolo convencionalmente utilizado além de apresentarem excelente resistência.

PALAVRAS-CHAVE: Compósito, tijolo e casas populares.

\section{ABSTRACT \\ COMPOSITE GYPSUM AND STYROFOAM FOR CONSTRUCTION OF POPULAR HOUSES}

The use of new technologies by employing alternative materials, eco-friendly, is an innovation for the building industry not only for their excellent properties, but also by its low cost. This article will show a new type of composite material for building of popular houses, based on Styrofoam (polystyrene) and gypsum, which has compositions $(1.5,1), \quad(1: 1) \quad(1: 1.5)$ plaster with polystyrene in order to replace the traditional ceramic bricks conventionally used. It will be shown the test data for thermal conductivity and compression tests made on the proposed materials. It was demonstrated that the manufacturing cost of these alternative bricks is lower than those conventionally used besides presenting an excellent resistance.

KEY-WORDS: Composite, brick and housing. 


\section{MATERIAIS COMPÓSITOS À BASE DE GESSO E ISOPOR PARA CONSTRUÇÃO DE CASAS POPULARES}

\section{INTRODUÇÃO}

\section{A Questão da Habitação no Brasil}

A questão da habitação é um dos grandes problemas sociais do Brasil. O déficit habitacional para a população de baixa renda é estimado em 6,6 milhões de moradias. Uma dificuldade suplementar para a erradicação desse problema, além do alto número de moradias a serem construídas, é o custo elevado das obras da construção civil.

Diante disso, a Financiadora de Estudos e Projetos (FINEP), órgão do governo federal, vem subsidiando o Programa de Tecnologia para Habitação (HABITARE), cuja meta é pesquisar novas tecnologias para barateamento da construção de casas com interesse social (isto é, populares) com qualidade, no país.

A indústria da Construção Civil busca de maneira constante e insistente, materiais alternativos ecologicamente corretos, que venham atender as condições de redução de custos, agilidade de execução e durabilidade.

Portanto, faz-se necessária a pesquisa e o desenvolvimento de métodos capazes de estabelecer soluções técnicas e economicamente viáveis para o uso de recursos renováveis pelos setores da construção civil. Nesse contexto, o objetivo desse trabalho consiste em mostrar os procedimentos realizados na construção de uma tecnologia para barateamento da construção de casas com interesse social com qualidade no país e uma melhora no conforto térmico (SOUZA, 2002).

\section{REVISÃO BILIOGRÁFICA}

\section{Compósitos}

Os materiais compósitos estão entre os materiais mais antigos e mais recentes. É um material resultante da combinação de dois ou mais materiais, de composição e forma diferentes de cada constituinte mantém intacta a sua identidade, não havendo, por- tanto, nem dissolução nem fusão entre os vários constituintes. O objetivo principal em se produzir compósitos é de combinar diferentes materiais para produzir um único dispositivo com propriedades superiores às dos componentes unitários.

Ao combinar materiais com características e propriedades tão diferentes, pretende-se obter um composto onde as propriedades físicas e químicas dos constituintes se complementem, de forma a obter um material superior a qualquer um dos seus constituintes e adequado aos fins pretendidos. Com os materiais compósitos é possível obter produtos com diferentes propriedades, entre as quais se podem citar: leveza, ductilidade, materiais resistentes a altas temperaturas, materiais duros e resistentes ao choque.

A maioria dos estudos de compósitos visa à obtenção de um material com propriedades mecânicas, elétricas e ópticas mais adequadas para seu fim que os materiais convencionais. No campo térmico tem-se priorizado a obtenção de materiais que resistam a bruscos gradientes de temperatura e a altíssimas e baixíssimas temperaturas. No caso específico do presente trabalho, a 
busca é por um novo material que tenha um menor coeficiente de condutividade térmica para ser um bom isolante térmico e que também apresentam adequada resistência mecânica para propiciar seu manuseio e transporte (MACHADO, 2003).

\section{Aspectos Térmicos}

As propriedades térmicas como a condutividade ou a difusividade térmica dos materiais (por exemplo, isolantes, materiais de edificações) são necessárias ao dimensionamento de elementos de isolação, no desenvolvimento da aplicação de novos materiais e na simulação do desempenho térmico de edificações e de sistemas.

Usualmente estas propriedades são determinadas por métodos estacionários aplicados sobre amostras de tamanho suficiente para integrar todas as heterogeneidades do material. São feitas nesse caso a simples medição do fluxo de calor através da amostra (integrado ao longo do tempo) e da diferença de temperatura imposta ao material. Neste caso longos períodos são necessários à obtenção do regime permanente em ambiente termicamente estável.

Materiais porosos capazes de conter umidade não podem ser medidos por métodos estacionários devido à migração da umidade no interior da amostra sob efeito do gradiente de temperatura imposto e à conseqüente secagem do material.

Métodos transientes permitem a determinação simultânea da condutividade térmica e da difusividade térmica em tempos curtos sem a necessidade da operação em regime permanente, em contrapartida, é necessária a medição do fluxo de calor instantâneo em ambas as faces da amostra e de suas respectivas temperaturas.

\section{Conforto térmico}

Antes de definirmos conforto térmico, devemos lembrar que por ser homeotérmico, o homem necessita manter constante a temperatura interna de seu corpo; independente da temperatura externa do ambiente. Este equilíbrio é mantido por um sistema orgânico chamado termorregulador, que realiza trocas térmicas com o ambiente através de funções fisiológicas para manter a temperatura constante.

Segundo define a ASHRAE, Associação Americana dos Engenheiros de Refrigeração, $\mathrm{Ar}$ Condicionado e Aquecimento, Norma 55/81, conforto térmico é o estado de espírito que expressa a satisfação com o ambiente térmico. Essa sensação de bem estar térmico do corpo humano dependerá da atuação do sistema termorregulador para a manutenção do equilíbrio térmico, pois quanto maior for o trabalho desse sistema, maior a sensação de desconforto.

O equilíbrio térmico entre o corpo e o ambiente dependerá de fatores ambientais (temperatura do ar radiante, temperatura radiante térmica, umidade relativa e ventilação) e fatores individuais (atividade desenvolvida, taxa de metabolismo e resistência térmica da roupa). A combinação dessas variáveis, mesmo que diferentes, irão proporcionar sensações semelhantes, que é a sensação de conforto térmico.

Dada a própria definição subjetiva de conforto, e toda a gama de variáveis que podem interferir na sensação de bem estar térmico das pessoas, há uma clara dificuldade para determinar um índice que represente fielmente a sensação de conforto térmico. Os principais parâmetros considerados são: temperatura do ar, umidade relativa, velocidade do ar, 
temperatura radiante média, tipo de vestimenta e taxa média do metabolismo da atividade exercida.

O conforto térmico de um ambiente é essencial para a sensação de bem estar, humor e bom desenvolvimento das atividades dos usuários. Situações de desconforto por temperaturas extremas, falta de ventilação adequada, umidade excessiva combinada com temperaturas elevadas ou radiação térmica devida a superfícies aquecidas, podem ser bastante prejudiciais. Alguns efeitos físicos desse desconforto podem ser sonolência, alteração de batimentos cardíacos e aumento de sudação. Psicologicamente também se observam alguns efeitos como a apatia e desinteresses pelo trabalho.

\section{Resistência Térmica}

Fisicamente, a resistência térmica traduz-se como sendo a maior ou menor facilidade com que se dá o fluxo de calor em determinada direção. Pela equação 01, que é a resistência térmica, neste caso para uma parede plana, depende da geometria do material e de sua condutividade térmica (BEZERRA, 2003):

$$
R_{t}=\frac{L}{K . A}
$$

Onde:

$R_{t}$ - resistência térmica $(\mathrm{K} / \mathrm{w})$;

$\mathrm{L}$ - espessura da parede $(\mathrm{m})$;

$\mathrm{k}$ - condutividade térmica $(\mathrm{W} / \mathrm{mK})$;

A - área perpendicular ao fluxo de calor $\left(\mathrm{m}^{2}\right)$.

Analisando-se as equações acima se constata a possibilidade de redução da taxa de transferência de calor através de fechamentos opacos se esses forem construídos com materiais de baixa condutividade térmica, pois resultarão na redução da difusividade térmica e elevação da resistência térmica (BEZERRA, 2003).

\section{Carga Térmica}

Para determinar a quantidade total de calor que deve ser extraída ou fornecida a um ambiente construído para proporcionar conforto térmico aos usuários, deve-se determinar a carga térmica do ambiente, ou seja, a soma de todos os acréscimos e perdas de energia através do envelope da edificação (BEZERRA, 2003).

De acordo com Lamberts (1997), os principais fatores que contribuem para a carga térmica de um ambiente construído são: fatores climáticos (insolação, umidade, temperatura do ar externo), fator humano (número de ocupantes, tipo de atividade) e fator arquitetônico (tipo de iluminação, equipamentos existentes, número de renovações do ar, e tipos de fechamentos).

No caso dos fechamentos opacos, o ganho de calor é determinado simplesmente pelo produto da taxa de calor que o atravessa pela sua área; matematicamente descrito como (BEZERRA, 2003):

$$
Q=q \cdot A
$$

Equação (02) 
Onde:

$q$ - fluxo de calor $\left(\mathrm{W} / \mathrm{m}^{2}\right)$;

$\mathrm{Q}$ - taxa de fluxo de calor (W);

A - área da superfície que participa do processo de transferência de calor $\left(\mathrm{m}^{2}\right)$.

\section{Inércia Térmica}

Um sólido retém parte da energia que flui entre suas faces. A quantidade que ficará retida depende da capacidade térmica do material que constitui o sólido. Essa característica dos corpos é denominada de inércia térmica. Materiais com elevada inércia térmica permitem diminuir a amplitude de variação da temperatura no interior das edificações. Dessa forma, os picos de temperatura interna dos ambientes podem ser modificados para reduzir as sensações de desconforto devido ao "calor" ou ao "frio" (BEZERRA, 2003).

\section{Transferência de calor}

\section{Transferência de Calor entre o Meio e o Ambiente Construído}

Uma edificação absorve energia térmica do meio externo através dos mecanismos de radiação e convecção. A temperatura de sua face externa eleva-se em relação à temperatura inicial e, como a temperatura da face interna é menor, ocorrerá um fluxo de calor por condução na direção desta última. A intensidade desse fluxo dependerá, entre outros fatores, da espessura da parede (L), da capacidade calorífica do material (cp), de sua densidade ( $\rho$ ) e de sua condutividade térmica (k). Em conseqüência da elevação da temperatura, haverá um fluxo de calor da face interna da parede para o ambiente interno, através dos mecanismos de radiação e de convecção (BEZERRA, 2003).

Para determinar a influência que o tipo de material tem sobre a intensidade de fluxo através da parede, utiliza-se à propriedade térmica denominada de condutividade térmica $(\mathrm{k})$. Materiais bons condutores de calor têm valores de $k$ elevados - para o alumínio, por exemplo, $\mathrm{k}_{\mathrm{Al}}$ $=237 \mathrm{~W} / \mathrm{m}_{\mathrm{K}}$; a $300 \mathrm{~K}$ (INCROPERA; DEWITT, 1998). Quanto maior o valor de $\mathrm{k}$, maior será o fluxo de calor através da parede e, portanto, a temperatura da face interna.

Materiais que possuem baixa densidade (cortiça, EPS, lã de vidro e concreto celular), tabela 1, têm baixa condutividade principalmente devido à porosidade que apresentam. Neles, o ar confinado no interior dos poros dificulta a transferência de calor (LAMBERTS, 1997).

Tabela 1: Densidade de alguns materiais utilizados na construção civil.

\begin{tabular}{|cc|}
\hline MATERIAL & DENSIDADE $(\mathrm{g} / \mathrm{ml})$ \\
\hline EPS & 0,025 \\
\hline Gesso & 0,8 \\
Cimento & 1,2 \\
Areia Fina & 1,4 \\
\hline
\end{tabular}

\section{Materiais Poliméricos Agregados ao Cimento Portland}

A aplicação na construção civil de materiais poliméricos é bastante difundida na atualidade, sendo um caminho viável de reaproveitar materiais recicláveis. 
A associação de vários materiais ao concreto tem se mostrado um caminho eficaz na melhora das propriedades mecânicas tais como resistência a compressão e a tração, durabilidade e propriedades químicas (FOWLER, 1998). A utilização de resíduos como matéria-prima na fabricação de elementos construtivos apresenta vantagens do ponto de vista técnico (por exemplo, desempenho térmico) quanto dos pontos de vista econômico e ambiental.

Para Cassa (2001), o lixo doméstico não apresenta potencial de aproveitamento como matéria-prima para produção de materiais de construção, por outro lado, o autor admite que a reciclagem de vidro, plástico, metal e papel que possibilitam a redução do volume de lixo depositado nos aterros, além de economizar recursos naturais, gerando emprego e renda.

Para Santana (2001), a utilização de agregados reciclados em argamassas de revestimento constitui uma alternativa viável. As argamassas produzidas com agregado reciclado têm apresentado desempenho significativamente superior ao das argamassas convencionais. Observou-se em alguns casos que, em função do teor de materiais cerâmicos presentes, a utilização de agregados reciclados permitiu uma redução de $30 \%$ no consumo de cimento da argamassa e um incremento nas propriedades mecânicas. Carneiro (2001) destacou, ainda, outros materiais passíveis de serem reciclados e que compõem o entulho proveniente da construção civil: plásticos, borracha e papelão, todos classificados como resíduos inertes, conforme a NBR 10004. Em função das limitações técnicas atuais, o processo para reciclagem desses resíduos nem sempre é economicamente viável.

Em artigo recentemente publicado (MOREL; GOURC, 1997), uma extensiva revisão a cerca dos aspectos gerais do comportamento de solos granulares reforçados com fibras poliméricas discretas foi apresentada. A inclusão de fibras poliméricas no solo cimentado, definitivamente proporciona uma melhoria nas características de resistência e ductilidade do material.

O reforço de solos pela utilização conjunta de fibras e agentes cimentantes, contudo, não tem sido suficientemente investigado, principalmente em termos de deformabilidade, interação entre os teores de cimento e fibra e comportamento residual. Pode-se citar o trabalho precursor de Maher e Ho (1993) que apresenta um estudo básico à cerca do comportamento mecânico de uma areia artificialmente cimentada reforçada com fibras de vidro, e alguns trabalhos recentes realizados no Brasil (CONSOLI, 1997).

De modo geral, pode-se esperar que a adição de fibras poliméricas aos solos artificialmente cimentados altere positivamente suas propriedades mecânicas: maior ductilidade pós-fissuração da matriz cimentada, maior capacidade de absorção de energia e maior resistência ao impacto e à fadiga.

Bezerra (2003) realizou análise experimental do desempenho térmico de sistema construtivo (parede), fabricado com blocos de concreto leve com EPS como agregado graúdo. Foram comparados os resultados com aqueles obtidos com bloco de concreto comum, que demonstraram a viabilidade do uso o loco de concreto leve tanto no que diz respeito à resistência mecânica como no que se refere ao desempenho térmico.

\section{Isopor (EPS) \\ Propriedades e Características}

Poliestireno expandido é um plástico rígido;

Leveza - as densidades do isopor variam entre os $10-30 \mathrm{~kg} / \mathrm{m}^{3}$; 
Baixa condutibilidade térmica, ou seja, capacidade de isolamento térmico;

Resistência mecânica - apesar de muito leve, o isopor tem uma resistência mecânica elevada;

Baixa absorção de água - o isopor não é higroscópico. Mesmo quando imerso em água o isopor absorve apenas pequenas quantidades de água;

Fácil de manusear;

Econômico - tomando em conta os diversos parâmetros como as quebras, mão de obra, manuseamento, baixo peso, transporte, armazenagem, a embalagem em isopor resulta economicamente vantajosa.

Gesso

\section{Propriedades e características}

Um mineral composto fundamentalmente de sulfato de cálcio hidratado $\left(\mathrm{CaSO}_{4} \cdot 2 \mathrm{H}_{2} \mathrm{O}\right)$;

Em geral tem cor branca, mas impurezas diversas podem dar-lhe aspecto acinzentado, amarelado, rosado ou marrom;

Baixo coeficiente de condutibilidade térmica sendo considerado um isolante térmico;

Boa característica do gesso é seu baixo impacto ambiental.

Aplicações

Construção civil para acabamento do reboco e do teto das habitações;

O gesso entra também na composição do cimento portland, na proporção de dois a três por cento, como agente retardador de pegas;

Em aparelhos ortopédicos, em trabalhos de prótese dentária.

\section{MATERIAIS E MÉTODOS}

\section{Procedimento Para fabricação do compósito (gesso mais isopor)}

\section{Trituração do isopor}

O primeiro procedimento para fabricação do compósito a base de gesso e Isopor foi a trituração do isopor como visto na Figura 1.

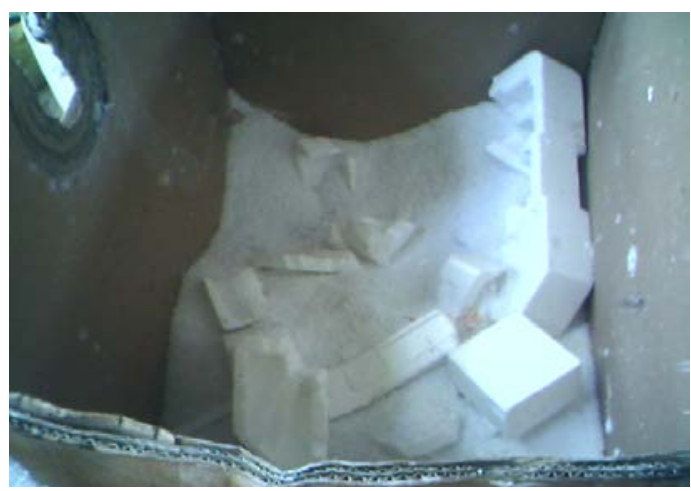

Figura 1: Isopor. 


\section{Armazenamento do isopor triturado}

O passo seguinte foi o armazenamento do isopor, mostrado na figura 2, pois era necessário o armazenamento em um local apropriado.

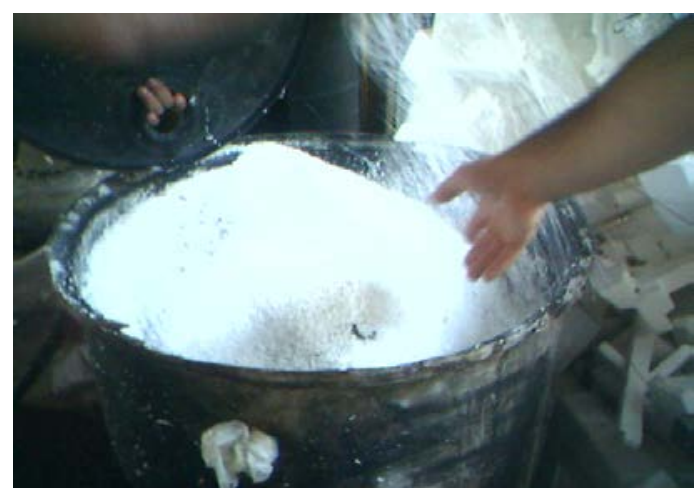

Figura 2: Isopor triturado armazenado em recipiente.

\section{Mistura}

A Figura 3 mostra a mistura do compósito, realizada através de proporções que são indicadas na tabela 02.

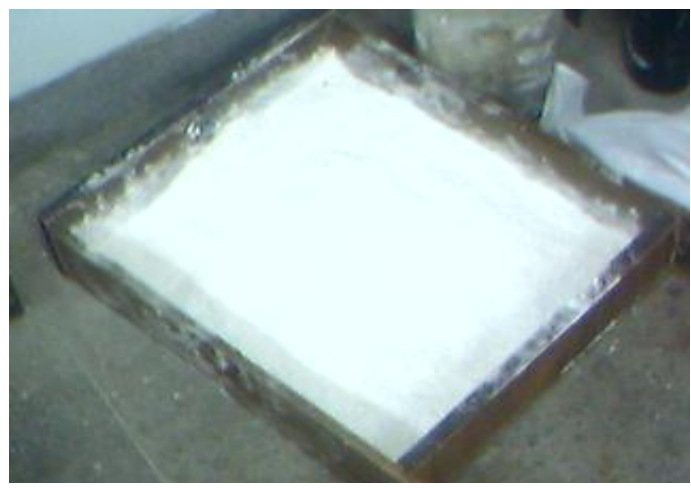

Figura 3: Mistura do compósito.

Tabela 02: Misturas do Compósito.

\begin{tabular}{cccc}
\hline Misturas & Gesso & EPS(Isopor) & Água \\
\hline Mistura 1 & 1,0 & 1,0 & 0,5 \\
Mistura 2 & 1,0 & 1,5 & 0,5 \\
Mistura 3 & 1,5 & 1,0 & 0,5 \\
\hline
\end{tabular}


A Figura 4 apresenta o processo de confecção do molde do compósito.

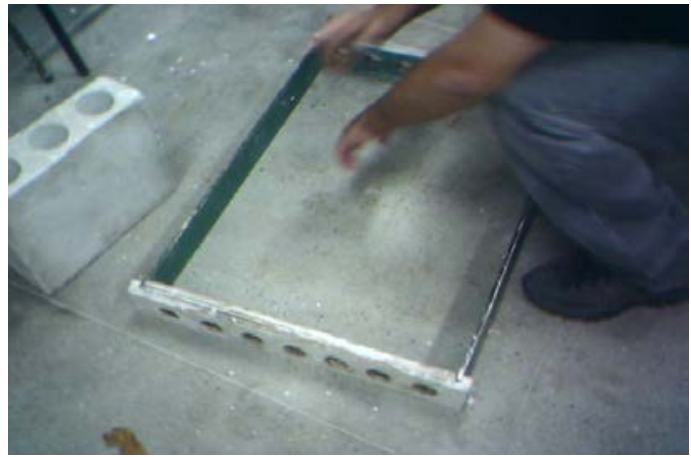

Figura 4: Molde do compósito.

Aplicação da amostra do compósito à base de gesso e isopor está mostrada na tabela 03, onde apresenta a figura 05 apresenta a aplicação da amostra e a figura 06 a casa popular com compósito.

Tabela 03: Aplicação do compósito.

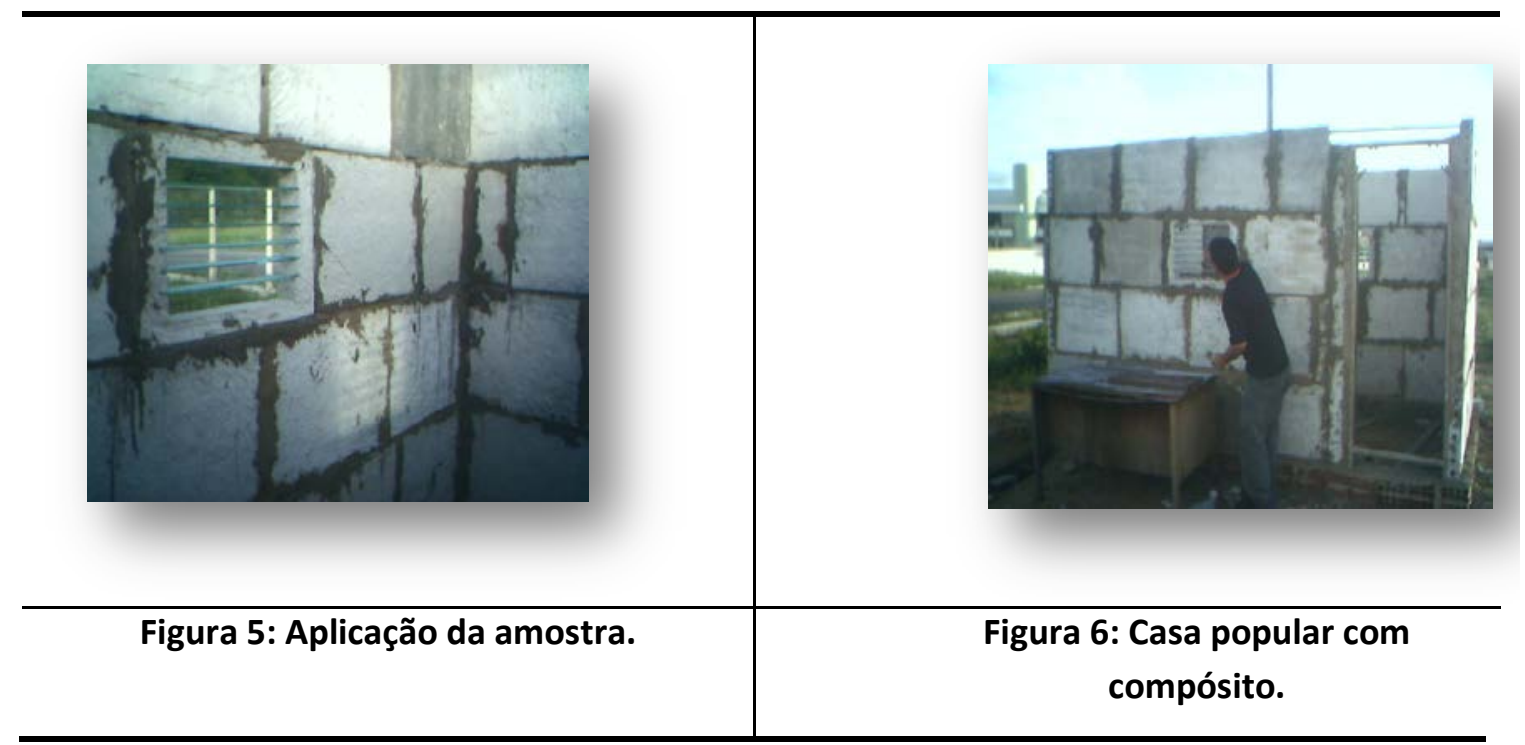

\section{RESULTADOS}

A tabela 4 mostra os resultados dos ensaios referentes à condutividade térmica do compósito e a tabela 5 apresenta os valores dos ensaios referentes da resistência à compressão. 
Tabela 4: Condutividade Térmica do Compósito.

\begin{tabular}{|cc|}
\hline CONDUTIVIDADE TÉRMICA & $\mathrm{K}(\mathrm{w} / \mathrm{mk})$ \\
\hline Gesso & 0,49 \\
\hline $\begin{array}{c}\text { Gesso + Isopor } \\
1,5: 1\end{array}$ & 0,36 \\
\hline $\begin{array}{c}\text { Gesso + Isopor } \\
1: 1\end{array}$ & 0,25 \\
\hline $\begin{array}{c}\text { Gesso + Isopor } \\
1: 1,5\end{array}$ & 0,25 \\
\hline
\end{tabular}

Tabela 5: Resistência a Compressão do Compósito.

\begin{tabular}{|cc|}
\hline AMOSTRAS & RESISTÊNCIA COMPRESSÃO (Mpa) \\
\hline $\mathbf{1}$ & 5,24 \\
$\mathbf{2}$ & 5,44 \\
$\mathbf{3}$ & 5,19 \\
$\mathbf{4}$ & 5,64 \\
$\mathbf{5}$ & 6,04 \\
$\mathbf{6}$ & 5,50 \\
\hline Média & 5,50 \\
\hline
\end{tabular}

\section{CONCLUSÕES}

Foi observado que a mistura com proporção maior para o isopor mostrou menor condutividade, logo o material apresenta apresenta um melhor conforto térmico.

Houve um barateamento na construção da casa devido o uso dos materiais alternativos e seu processo de fabricação.

O uso do compósito na construção foi satisfatório devido as suas propriedades e custo de produção, destacando os resultados de resistência à compressão e condutividade térmica.

O processo tecnológico de fabricação da casa com o uso do compósito proposto é simples podendo ser repassado para as comunidades que possam fabricar tais unidades em regime de mutirão.

\section{REFERÊNCIAS}

1. ASHRAE, American Society of Heating, Refrigerating and Air Conditioning Engineers ANO.

BEZERRA L. A. C. Análise do Desempenho Térmico de Sistema Construtivo de Concreto com EPS como Agregado Graúdo. Programa de Pós-Graduação em Engenharia Mecânica/UFRN, Natal RN, f. 64, Outubro, 2003.

2. CASSA, J. C. S. Diagnóstico dos setores produtores de resíduos na região metropolitana de Salvador/Bahia. In: 2001. 
3. CONSOLI, N.C.; ULBRICH, L.A. E PRIETTO, P.D.M. Engineering behaviour of randomly distributed fiber-reinforced cemented soil, Symp. on Recent Developments on Soil and Pavement Mechanics, Rio de Janeiro, Brasil, Vol.1, p.481-486, 1997.

4. FOWLER, D. W. Current status of polymer concrete in the United States. In: INTERNATIONAL CONGRESS ON POLYMER IN CONCRETE,p.9, 1998.

5. INCROPERA, F. P. e DEWITT, D. P., Fundamentos de Transferência de Calor e de Massa 4a Ed., LTC - Livros Técnicos e Científicos Editora S.A, 1998.

6. LAMBERTS, R., DUTRA, L., PEREIRA, F.O.R. Eficiência energética na arquitetura São Paulo: P.W.; 192, 1997.

7. MACHADO,M.,Materiais Compósitos, Editora da Faculdade de Engenharia da

Universidade do Porto, Cidade do Porto, Portugal, 2003.

8. MAHER,M.H. ANDHO,Y.C., "Behavior of Fiber-ReinforcedCemented SandUnder Static and Cyclic Loads", Geotechnical Testing Journal, ASTM, Vol. 16, No. 3, pp. 330-338, 1993.

9. MOREL, J. C.; GOURC, J. P. Mechanical behavior of sand reinforced with mesh elements.Geosynthetics International, v. 4, n. 5, p. 481-508, 1997.

10. SANTANA, M. J. A.; CARNEIRO, A. P.; SAMPAIO, T. S. argamassas de revestimento. In: CASSA, J. C. S.; CAR (org.). Reciclagem de entulho para a produção de mat EDUFBA; Caixa Econômica Federal, P 262- 269, 2001.

11. SOUZA, L.M., Viabilidades térmica, econômica de materiais compósitos, 2002. 